\title{
Patient- and Caregiver-Reported Burden of Transfusion-Dependent $\beta$-Thalassemia Measured Using a Digital Application
}

\author{
Clark Paramore $^{1} \cdot$ Laurice Levine $^{2} \cdot$ Emma Bagshaw $^{3}$ (1) $\cdot$ Chengyu Ouyang $^{3} \cdot$ Amber Kudlac $^{3} \cdot$ Mark Larkin $^{3}$
}

Accepted: 5 October 2020 / Published online: 30 October 2020

(c) The Author(s) 2020

\begin{abstract}
Background and Objective Transfusion-dependent $\beta$-thalassemia (TDT) is a rare genetic disease characterized by a deficiency of functional $\beta$-globin, ultimately leading to lifelong dependence on blood transfusions. There is little patient- and caregiverreported data with which to understand the holistic and societal impact of TDT. The objective of this study was to evaluate the patient- and caregiver-reported disease-management, symptom, and quality-of-life burden of TDT.

Methods We conducted a prospective, observational, real-world study of adults with TDT and caregivers of adolescents with TDT, in Italy, the UK, and the USA. Over 90 days, participants used a smartphone application to respond to surveys about their or their dependent's TDT, including bespoke background and disease-management surveys, the Brief Fatigue Inventory (BFI), the Transfusion-dependent Quality of life questionnaire (TranQol), and the Brief Pain Inventory Short Form (BPI-SF). Results Eighty-five individuals participated. Mean BFI and TranQol scores on enrollment were $5.0(0-10$ scale; $10=$ worst symptoms) and $51(0-100$ scale; $100=$ best quality of life), respectively. Mean transfusion frequency was every 3.2 weeks. Mean time spent on TDT management was $592 \mathrm{~min}$ on transfusion days and $91 \mathrm{~min}$ on non-transfusion days (11 h per week). Mean BFI and BPI-SF "worst fatigue" and "worst pain" scores were higher in the 5 days pre-transfusion than in the 5 days post-transfusion (fatigue 5.05 vs 4.29 ; pain 4.33 vs 3.85 ; 0 - 10 scale; $10=$ worst symptoms).
\end{abstract}

Conclusions The patient- and caregiver-reported burden of TDT is high, influenced by disease-management time, fatigue, pain, and quality-of-life impairment.

Electronic supplementary material The online version of this article (https://doi.org/10.1007/s40271-020-00473-0) contains supplementary material, which is available to authorized users.

\section{Emma Bagshaw}

emma.bagshaw@vitaccess.com

bluebird bio, Cambridge, MA, USA

2 Self-Employed Medical Consultant, San Francisco, CA, USA

3 Vitaccess Ltd, 2nd Floor Nucleus House, 2 Lower Mortlake Road, Richmond, Greater London TW9 2JA, UK

\section{Key Points for Decision Makers}

Transfusion-dependent $\beta$-thalassemia appears to place a high level of burden on individuals with the condition and their caregivers.

In our study, the burden associated with transfusiondependent $\beta$-thalassemia was driven by a high time spent on disease management, fatigue and pain symptoms, and impairment to quality of life.

\section{Introduction}

$\beta$-Thalassemia is a rare genetic disease characterized by reduced or absent production of functional $\beta$-globin necessary to form adult hemoglobin [1]. This results in impaired red blood cell function, leading in severe cases to chronic 
anemia, serious morbidity, and a shortened lifespan compared with the general population [1]. Individuals with the most severe form of the disease, transfusion-dependent $\beta$-thalassemia (TDT), are reliant on regular blood transfusions [1].

The need for regular blood transfusions and daily chelation therapy to reduce transfusion-related iron overload can be burdensome for individuals with TDT and their families. This is driven by factors such as the high amount of time spent managing the condition, time spent in the healthcare setting [2,3], out-of-pocket treatment costs [4, 5], and the management of adverse events [1].

It is important to further understand this burden to inform improvements in long-term care and health-related quality of life (HRQoL) in individuals with TDT. However, there is currently little high-quality evidence on which to act. Although multiple studies have evaluated HRQoL in TDT [6-16], only a handful have employed disease-specific instruments [13-16]. Additionally, little evidence has been collected in the real-world setting. There is, therefore, a need for real-world data on disease burden and HRQoL in individuals living with TDT.

We report on a real-world smartphone-based study exploring the burden of TDT from the patient and informal caregiver perspective. The objectives were to evaluate the real-world disease-management and symptom burden of the condition, as well as the HRQoL of individuals with TDT in Italy, the UK, and the USA.

\section{Methods}

\subsection{Study Design}

We conducted a prospective, observational, longitudinal, real-world, patient-reported outcome (PRO) study. Adults with TDT and informal caregivers of adolescents with the condition used a bespoke smartphone application (app) developed for the study, myThalLog (Vitaccess Limited, London, UK), to enter daily data about their or their dependent's TDT, its management, and its impact on their lives, over a period of 90 days. Ethics approval was granted by a central independent institutional review board (Salus Institutional Review Board, Austin, TX, USA).

\subsection{Participants}

Adults (aged $\geq 18$ years) with TDT and caregivers of adolescents aged $12-17$ years with TDT were eligible to participate in the study. Transfusion-dependent $\beta$-thalassemia was defined as a participant-reported diagnosis of $\beta$-thalassemia that, at the time of enrollment, was treated with a blood transfusion at least every 6 weeks. Exclusion criteria were prior receipt by the individual with TDT of an allogeneic hematopoietic stem cell transplant or participation in a gene therapy clinical trial.

\subsection{Recruitment, Screening, and Enrollment}

Participants were recruited from Italy, the UK, and the USA. Recruitment was community based, with potential participants made aware of the study via patient advocacy group communications, social media, and word of mouth. The myThalLog app was made available to the public in Google Play and the Apple App Store on the following dates: USA: 23 August 2018, UK: 17 October 2018, Italy: 27 November 2018. Enrollment was permitted at any time between the app launch and 90 days prior to the study closure on 30 September 2019.

Potential participants downloaded myThalLog onto their phones, before completing an in-app screening survey to check their eligibility. They then provided informed consent by reading and acknowledging their agreement with on-screen briefing and informed consent materials.

The digital app-based study approach was selected for several reasons. We hypothesized that online study promotion, and the ability for participants to enroll at home using their own devices, could drive rapid recruitment, as well as geographic and demographic diversity [17, 18]. Additionally, as smartphone apps can allow participants to enter data at times and places convenient to them, we hoped that this approach would promote data granularity and completeness, with a low impact of recall bias [18].

\subsection{Data Acquisition}

Participants were asked to provide data about their HRQoL, symptoms, and TDT management over a period of 90 days, via a selection of validated PRO instruments and bespoke surveys. Patient-reported outcome instrument and survey selection was based on (1) a targeted review of the literature, including previous research evaluating PROs in TDT and other indications requiring transfusions (e.g., Porter et al. [19]; Trachtenberg et al. [20]), (2) interviews with individuals who had TDT, and (3) a review of PRO-instrument databases (e.g., PROQOLID, https://www.eprovide. mapi-trust.org/). The literature review identified concepts that were important to individuals with TDT, including symptoms (e.g., pain, lack of energy/fatigue), the impact on the patient's ability to maintain their day-to-day role, and the impact on broader aspects of life, including physical, emotional, psychological, and social health $[15,21]$. Ultimate selection of instruments was driven by their ability to measure these concepts of interest, and suitability for administration via a smartphone app. No instrument could be identified that adequately evaluated the burden of time 
spent by patients and caregivers on TDT management. For this concept, a bespoke disease-management survey was developed, details of which are provided below. Copies of PRO instruments were evaluated for representation of the concepts of interest, evidence of content validity, and psychometric properties. The shortlist of instruments demonstrated good representation of important concepts, good psychometric measurement properties, and avoided the overlap of concepts, thus reducing respondent burden. Two TDT patient advocates reviewed the proposed instruments and provided feedback on their relevance to people with the condition. The advocates were chosen because they had strong networks of other individuals with TDT with whom they could consult on this topic, and a good understanding of the research process. Following their feedback, final instrument selection was made. Patient-reported outcome instruments and surveys presented to study participants were as follows.

\subsubsection{Background Survey}

A bespoke background survey asked participants about demographics, thalassemia characteristics, and the diagnosis and treatment of the individual with TDT. Participants were asked to complete the survey once, immediately following enrollment.

\subsubsection{Brief Fatigue Inventory}

The BFI was originally developed to assess fatigue in patients with cancer [22]. The tool has since been validated and used to assess fatigue in many indications and population groups [23-29], including people receiving blood transfusions and those with hemoglobinopathies [30, 31]. In this study, the BFI was completed by adults with TDT and by caregivers acting as proxies for their dependents. Participants were asked to compete the full BFI once, immediately following enrollment, and the "worst fatigue" question, which asks respondents to rate their fatigue at its worst in the past $24 \mathrm{~h}$, daily. The "worst fatigue" question was presented to participants as part of a question pair, at the same time as the Brief Pain Inventory Short Form (BPI-SF) "worst pain" question.

\subsubsection{Transfusion-Dependent Quality-of-Life Questionnaire}

The Transfusion-dependent Quality of life questionnaire (TranQol) is a TDT-specific survey used to assess HRQoL across the following domains: emotional health, family functioning, career/school functioning, and physical health [15]. The TranQol was completed by adults with TDT and by caregivers acting as proxies for their dependents. Participants were asked to complete the survey once, immediately following enrollment.

\subsubsection{Disease-Management Survey}

A bespoke disease-management survey assessed daily time spent on TDT management. Participants were asked to report time spent on transfusion-related activities, including travel, waiting time, and transfusion duration, plus any other disease-management activities they had carried out that day. Time for these additional activities was reported by selecting the relevant activity from a list of potential tasks. Two versions of the survey were developed: adult TDT patient self-report and adolescent caregiver report. The caregiver version asked participants to report time spent by just their dependent on transfusion-related activities, and time spent by both themself and their dependent on any other diseasemanagement activities (i.e., the total combined time for both people). Participants were asked to complete the survey daily. A copy of this is available as Electronic Supplementary Material.

\subsubsection{Brief Pain Inventory Short Form}

The Brief Pain Inventory (BPI) was originally developed to assess pain in patients with cancer [32]. The tool and its short-form version, the BPI-SF, have since been validated and used to assess fatigue in many indications and population groups[33-37]. Participants were asked to complete only the "worst pain" question, which asks respondents to rate their pain at its worst in the past $24 \mathrm{~h}$. The question was completed by adults with TDT and by caregivers acting as proxies for their dependents. Participants were asked to complete the question daily. It was presented as part of a question pair, at the same time as the BFI "worst fatigue" question.

\subsubsection{Survey Administration and Completion}

Participants were asked to complete all PRO instruments and surveys at enrollment. They were then asked to complete the disease-management survey, and BFI "worst fatigue" and BPI-SF "worst pain" question pair daily over the 90-day study period. Within each data entry window, participants were able to respond to the surveys at times of their choosing and complete them in any order. Missing the data entry window, submitting an incomplete survey, or failing to complete all the required surveys on any day did not prevent continued participation.

To encourage survey completion, participants were rewarded with virtual tokens (stars and medals), which could be collected and redeemed for Amazon digital vouchers, up to a maximum value of US $\$ 450$, or equivalent. The effectiveness of positive token economies in promoting and maintaining desired behavior is well established [38], with mobile app technology permitting sophisticated and effective implementation via "gamification" [39]. 


\subsection{Statistical Analysis}

Analysis was exploratory, to understand the distribution of the data, rather than to test specific hypotheses. All data were aggregated and pseudonymized prior to analysis. Participants were included in the analysis if they responded to at least one item in any survey at any time. Each survey was analyzed independently, with participants included in the analysis for a particular survey if they responded to at least one item in that survey at any required time point.

Results for the disease-management survey were calculated separately for days on which participants did or did not report receiving transfusions: transfusion days and nontransfusion days. For the BFI "worst fatigue" and BPI-SF "worst pain" questions, individual participant scores were analyzed for the period 5 days pre- and post-transfusion, as calculated from transfusion dates reported in the diseasemanagement survey.

Patient-reported outcome instruments were scored as per their scoring manuals. Minimal clinically important differences (MCIDs) for changes in BFI "worst fatigue" and BPI-SF "worst pain" scores were based on those for similar disease populations, as disease-specific MCIDs were not available.

\section{Results}

\subsection{Participants}

Eighty-five participants responded to at least one item in any survey and were included in the analysis. Eighty-one identified as adults with TDT ( $\beta$-thalassemia treated with blood transfusions at least every 6 weeks) and four identified as caregivers of adolescents with TDT. Participant flow is presented in Fig. 1.

For surveys that were presented daily during the study, participants responded on average just under half of the time (mean proportion of days completed: disease-management survey $45.1 \%$, BFI "worst fatigue" and BPI-SF "worst pain" question pair $44.6 \%$ ). Almost one-quarter of participants responded to these surveys every time they were presented (disease-management survey $24.3 \%$ of participants, BFI "worst fatigue" and BPI-SF "worst pain" question pair $23.4 \%$ of participants).

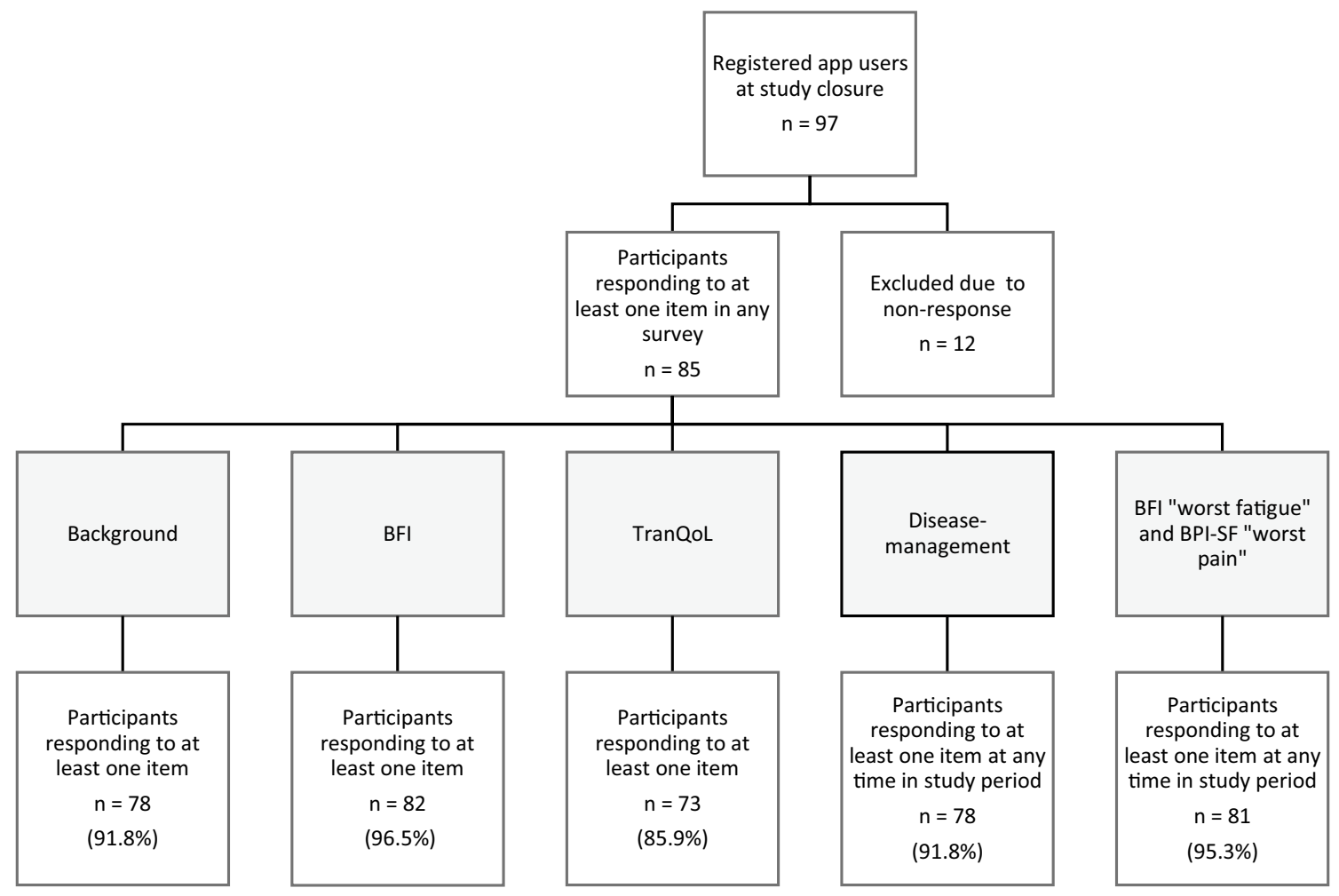

Brief Fatigue Inventory, BPI-SF Brief Pain Inventory Short Form, TranQol Transfusion-dependent Quality of life questionnaire

Fig. 1 Participant flow 


\subsection{Demographics}

Demographic and clinical characteristics of all individuals with TDT in the overall analysis population (self-reported, $n=81$; caregiver reported, $n=4$ ) are provided in Table 1 .

\subsection{Brief Fatigue Inventory}

Eighty-two participants responded to at least one item in the BFI. The BFI score distribution is presented in Fig. 2a. Mean BFI score at enrollment was 5.0 (standard deviation [SD] $3.0 ; 0-10$ scale; $10=$ worst symptoms).

\subsection{Transfusion-Dependent Quality-of-Life Questionnaire}

The TranQol score distribution is presented in Fig. 2b. Mean overall and domain scores are presented in Fig. 3. Mean TranQol score at enrollment was 51 (SD 20; 0-100 scale; $100=$ best HRQoL).

\subsection{Disease-Management Survey}

\subsubsection{Transfusion Frequency}

Mean transfusion frequency during the 90-day study period was every 3.2 weeks (SD 1.5). The distribution of transfusion frequencies is presented in Fig. 2c.

\subsubsection{Disease-Management Time}

Daily time spent on TDT management on transfusion and non-transfusion days is presented in Table 2. On transfusion days, the mean daily time spent was 592 min (SD 349 min) or $9.8 \mathrm{~h}$. The activities associated with the greatest mean time were transfusions (352 min) and organizing payments from health insurance (152 min). On non-transfusion days, the mean daily time spent on TDT management was $91 \mathrm{~min}$ (SD $221 \mathrm{~min}$ ). This is equivalent to approximately $11 \mathrm{~h}$ per week in weeks without a transfusion. The activities associated with the greatest mean time were type- or cross-matching of blood (105 min per day) and arranging childcare (99 min).

On non-transfusion days, differences in the time spent on TDT management were seen between individuals who were receiving chelation via an infusion and those receiving oral therapy; Table 3. The mean daily time spent on TDT management by individuals receiving infused chelation and their caregivers on non-transfusion days was $336 \mathrm{~min}$ (SD $377 \mathrm{~min}$ ). Over the course of a week, this equated to $39 \mathrm{~h}$. For individuals receiving oral chelation and their caregivers, the mean daily time spent was $25 \mathrm{~min}$ (SD $49 \mathrm{~min}$ ). Over a week, this equated to $3 \mathrm{~h}$.
Table 1 Demographic and clinical characteristics of individuals with transfusion-dependent $\beta$-thalassemia

\begin{tabular}{|c|c|}
\hline Variable & $n(\%)$ \\
\hline Overall analysis population & $85(100.0)$ \\
\hline \multicolumn{2}{|l|}{ Country of residence $\mathrm{a}^{\mathrm{a}}$} \\
\hline UK & $58(68.2)$ \\
\hline USA & $20(23.5)$ \\
\hline Italy & $6(7.1)$ \\
\hline Germany $^{\mathrm{b}}$ & $1(1.2)$ \\
\hline \multicolumn{2}{|l|}{ Sex } \\
\hline Female & $45(52.9)$ \\
\hline Male & $32(37.6)$ \\
\hline Not reported & $8(9.4)$ \\
\hline \multicolumn{2}{|l|}{ Ethnicity } \\
\hline Indian & $16(18.8)$ \\
\hline Asian & $9(10.6)$ \\
\hline Other & $9(10.6)$ \\
\hline Pakistani & $9(10.6)$ \\
\hline White & $9(10.6)$ \\
\hline Any other Asian background & $6(7.1)$ \\
\hline Southern European & $4(4.7)$ \\
\hline Arab & $3(3.5)$ \\
\hline Bangladeshi & $3(3.5)$ \\
\hline Black or African American & $2(2.4)$ \\
\hline Chinese & $2(2.4)$ \\
\hline African & $1(1.2)$ \\
\hline Any other Black/African/Caribbean background & $1(1.2)$ \\
\hline Northern European & $1(1.2)$ \\
\hline Prefer not to answer & $2(2.4)$ \\
\hline Not reported & $8(9.4)$ \\
\hline \multicolumn{2}{|l|}{ Age, years } \\
\hline Median & 37.0 \\
\hline Range & $13-71$ \\
\hline \multicolumn{2}{|l|}{ Current thalassemia type } \\
\hline Major & $70(82.4)$ \\
\hline Intermedia & $6(7.1)$ \\
\hline Unknown & $1(1.2)$ \\
\hline Not reported & $8(9.4)$ \\
\hline \multicolumn{2}{|l|}{ Usual transfusion frequency, weeks } \\
\hline Mean & 3 \\
\hline Standard deviation & 1 \\
\hline Median & 3 \\
\hline Range & $1-4$ \\
\hline \multicolumn{2}{|l|}{ Chelation therapy } \\
\hline Oral & $44(51.8)$ \\
\hline Infusion & $18(21.2)$ \\
\hline Both oral and infusion & $14(16.5)$ \\
\hline Don't know/can't remember & $1(1.2)$ \\
\hline Not reported & $8(9.4)$ \\
\hline
\end{tabular}

${ }^{\text {a }}$ Seventy-eight of 85 participants completed at least one question in the background survey; participants not responding to certain items are labeled as 'not reported', apart from for the item 'country of residence', for which participant numbers could be derived from app download data

bone caregiver using the app in the UK reported their dependent's country of residence as Germany 


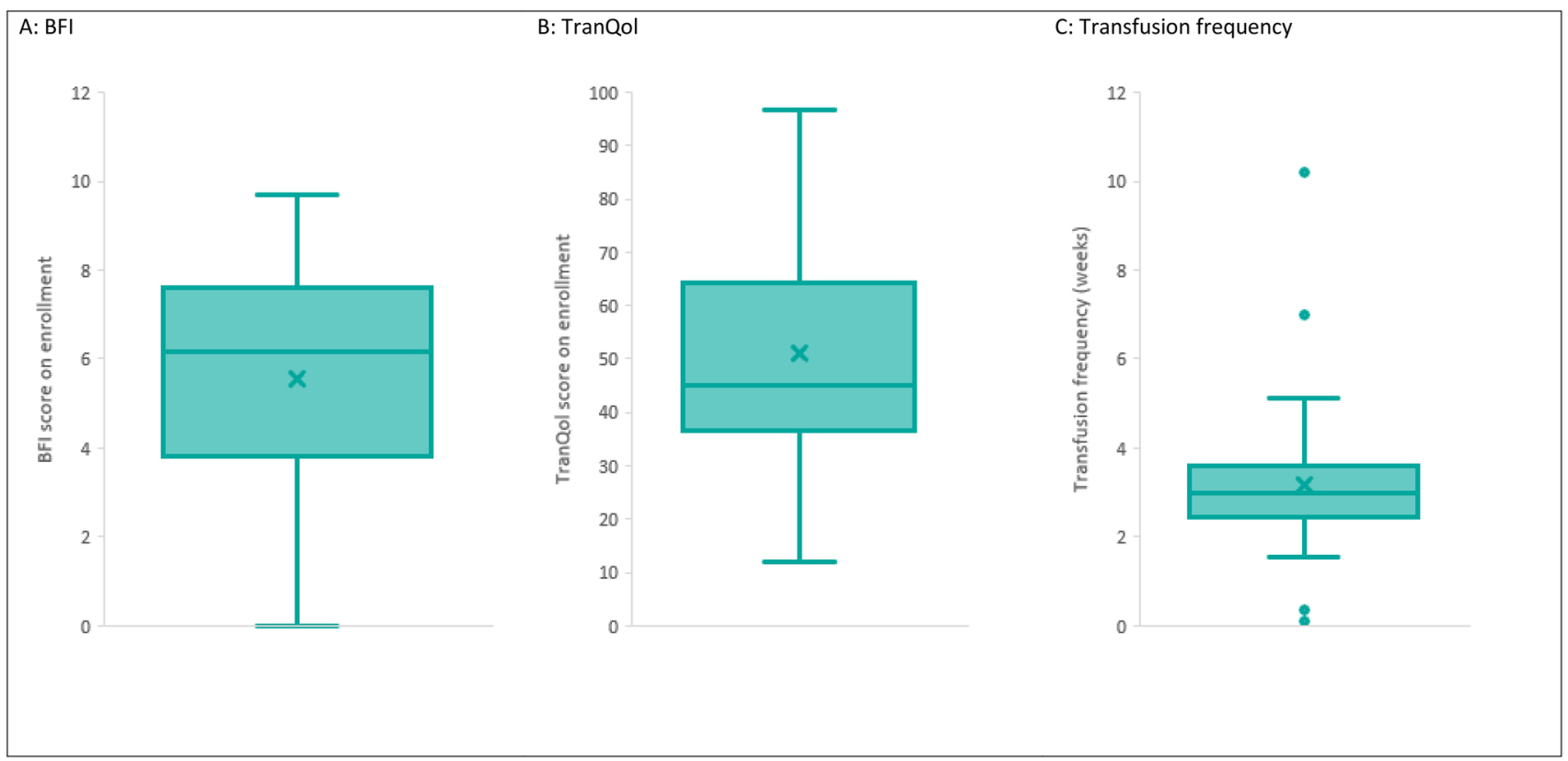

BFI, Brief Fatigue Inventory; TranQol, Transfusion-dependent Quality of life questionnaire

Fig. 2 Distributions: Brief Fatigue Inventory (BFI) score, Transfusion-dependent Quality of life questionnaire (TranQol) score, and transfusion frequency

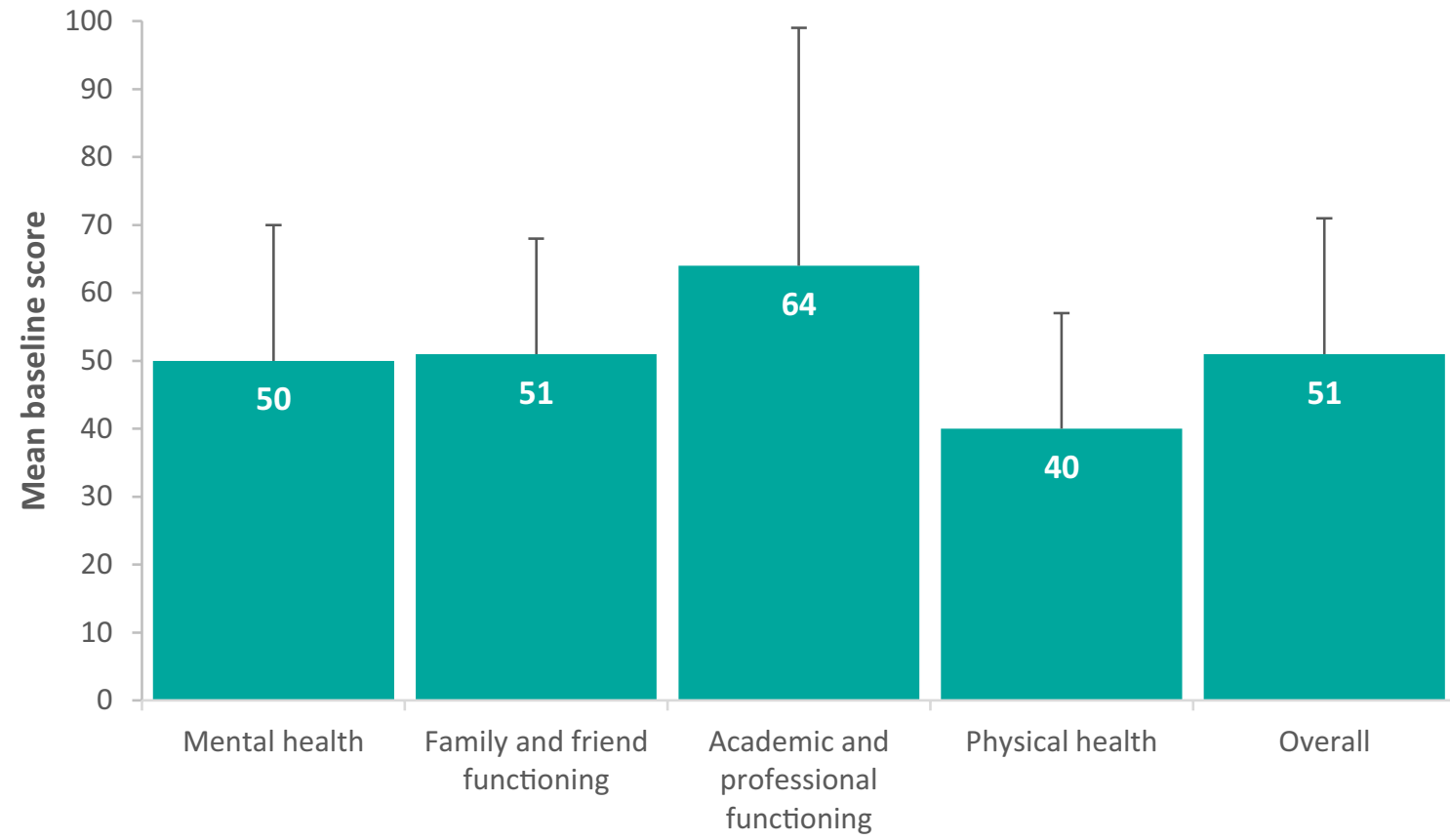

TranQol domain

Fig. 3 Transfusion-dependent Quality of life questionnaire (TranQol) overall and domain scores. Error bars indicate standard deviation

Differences in the time spent on TDT management were also observed between participants from the UK and USA. A comparison with Italy was not feasible owing to the very low number of participants. Participants in the USA spent more time each day on TDT management than did participants in the UK (USA: mean 164 min [SD 387 min], UK: mean 107 


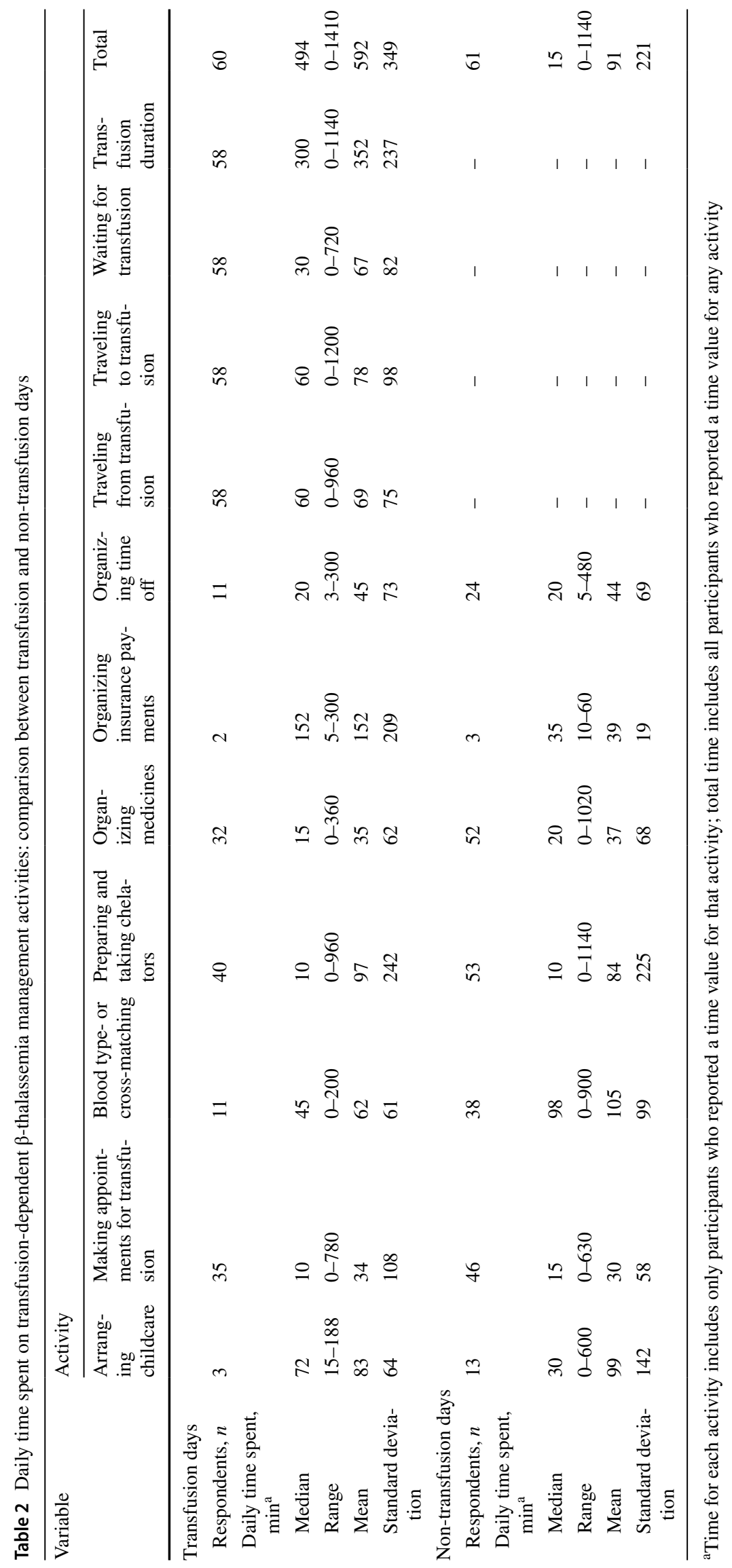


Table 3 Daily time spent on transfusion-dependent $\beta$-thalassemia management activities: non-transfusion days, comparison between infused and oral chelation

\begin{tabular}{|c|c|c|c|c|c|c|c|c|}
\hline \multirow[t]{2}{*}{ Variable } & \multicolumn{8}{|l|}{ Activity } \\
\hline & $\begin{array}{l}\text { Arrang- } \\
\text { ing child- } \\
\text { care }\end{array}$ & $\begin{array}{l}\text { Making appoint- } \\
\text { ments for transfu- } \\
\text { sion }\end{array}$ & $\begin{array}{l}\text { Blood type- or } \\
\text { cross-matching }\end{array}$ & $\begin{array}{l}\text { Preparing and } \\
\text { taking chela- } \\
\text { tors }\end{array}$ & $\begin{array}{l}\text { Organizing } \\
\text { medicines }\end{array}$ & $\begin{array}{l}\text { Organizing } \\
\text { insurance pay- } \\
\text { ments }\end{array}$ & $\begin{array}{l}\text { Organizing time } \\
\text { off }\end{array}$ & Total \\
\hline \multicolumn{9}{|l|}{ Infused chelation } \\
\hline Respondents, $n$ & 2 & 11 & 5 & 11 & 11 & 0 & 7 & 11 \\
\hline \multicolumn{9}{|l|}{$\begin{array}{l}\text { Daily time } \\
\text { spent, } \min ^{\mathrm{a}}\end{array}$} \\
\hline Median & 120 & 10 & 120 & 75 & 20 & - & 30 & 80 \\
\hline Range & $60-240$ & $3-70$ & $3-215$ & $0-1140$ & $3-300$ & - & $10-120$ & $0-1140$ \\
\hline Mean & 129 & 18 & 118 & 350 & 52 & - & 40 & 336 \\
\hline $\begin{array}{l}\text { Standard } \\
\text { deviation }\end{array}$ & 73 & 20 & 58 & 383 & 64 & - & 28 & 377 \\
\hline \multicolumn{9}{|l|}{ Oral chelation } \\
\hline Respondents, $n$ & 7 & 24 & 23 & 29 & 30 & 3 & 12 & 36 \\
\hline \multicolumn{9}{|l|}{$\begin{array}{l}\text { Daily time } \\
\text { spent, } \text { min }^{\mathrm{a}}\end{array}$} \\
\hline Median & 30 & 15 & 120 & 5 & 20 & 35 & 20 & 10 \\
\hline Range & $0-240$ & $0-630$ & $2-900$ & $0-600$ & $0-1020$ & $10-60$ & $5-480$ & $0-722$ \\
\hline Mean & 41 & 34 & 118 & 11 & 36 & 39 & 42 & 25 \\
\hline $\begin{array}{l}\text { Standard } \\
\text { deviation }\end{array}$ & 54 & 69 & 111 & 21 & 76 & 19 & 76 & 49 \\
\hline
\end{tabular}

${ }^{\text {a }}$ Time for each activity includes only participants who reported a time value for that activity; total time includes all participants who reported a time value for any activity

$\min [\mathrm{SD} 250 \mathrm{~min}])$. This difference was driven by higher mean time spent organizing insurance payments (USA: 57 min, UK: $0 \mathrm{~min}$ ), traveling to, from, and waiting for transfusions (USA: $277 \mathrm{~min}$, UK: $191 \mathrm{~min}$ ), and the duration of transfusion itself (USA: $597 \mathrm{~min}, \mathrm{UK}: 271 \mathrm{~min}$ ).

\subsection{Brief Fatigue Inventory "Worst Fatigue” and Brief Pain Inventory Short Form "Worst Pain" Questions}

Across the 5-day periods pre- and post-transfusion, 63 participants responded to the BFI "worst fatigue" and BPI-SF "worst pain" question pair.

\subsubsection{Brief Fatigue Inventory “Worst Fatigue”}

"Worst fatigue" scores for the 5-day periods pre- and posttransfusion are presented in Fig. 4. Mean "worst fatigue" score was 5.05 (SD 2.83) in the 5 days pre-transfusion, 5.55 (SD 2.95) on transfusion days, and 4.29 (SD 2.81) in the 5 days post-transfusion $(0-10$ scale; $10=$ worst symptoms $)$. The difference between mean scores on transfusion days and post-transfusion met the threshold for clinical relevance; MCID: 1 point [40].

\subsubsection{Brief Pain Inventory Short Form "Worst Pain"}

"Worst pain" scores for the 5-day periods pre- and posttransfusion are presented in Fig. 5. Mean "worst pain" score was 4.33 (SD 2.93) in the 5 days pre-transfusion, 4.93 (SD 3.09) on transfusion days, and 3.85 (SD 2.92) in the 5 days post-transfusion $(0-10$ scale; $10=$ worst symptoms $)$. The difference between mean scores on transfusion days and post-transfusion did not reach the threshold for clinical relevance; MCID: 2 points [41].

\section{Discussion}

In this international study of adults with TDT and caregivers of adolescents with TDT, the participant-reported burden of disease was considerable. Overall fatigue levels were moderate and HRQoL was low. Time spent on disease management was high, both on transfusion and non-transfusion days. The worst levels of fatigue and pain experienced by individuals with TDT increased in the lead-up to transfusion, before dropping post-transfusion.

The daily time burden facing individuals with TDT and their caregivers was considerable and multifaceted. Mean time spent on disease management was high, particularly 


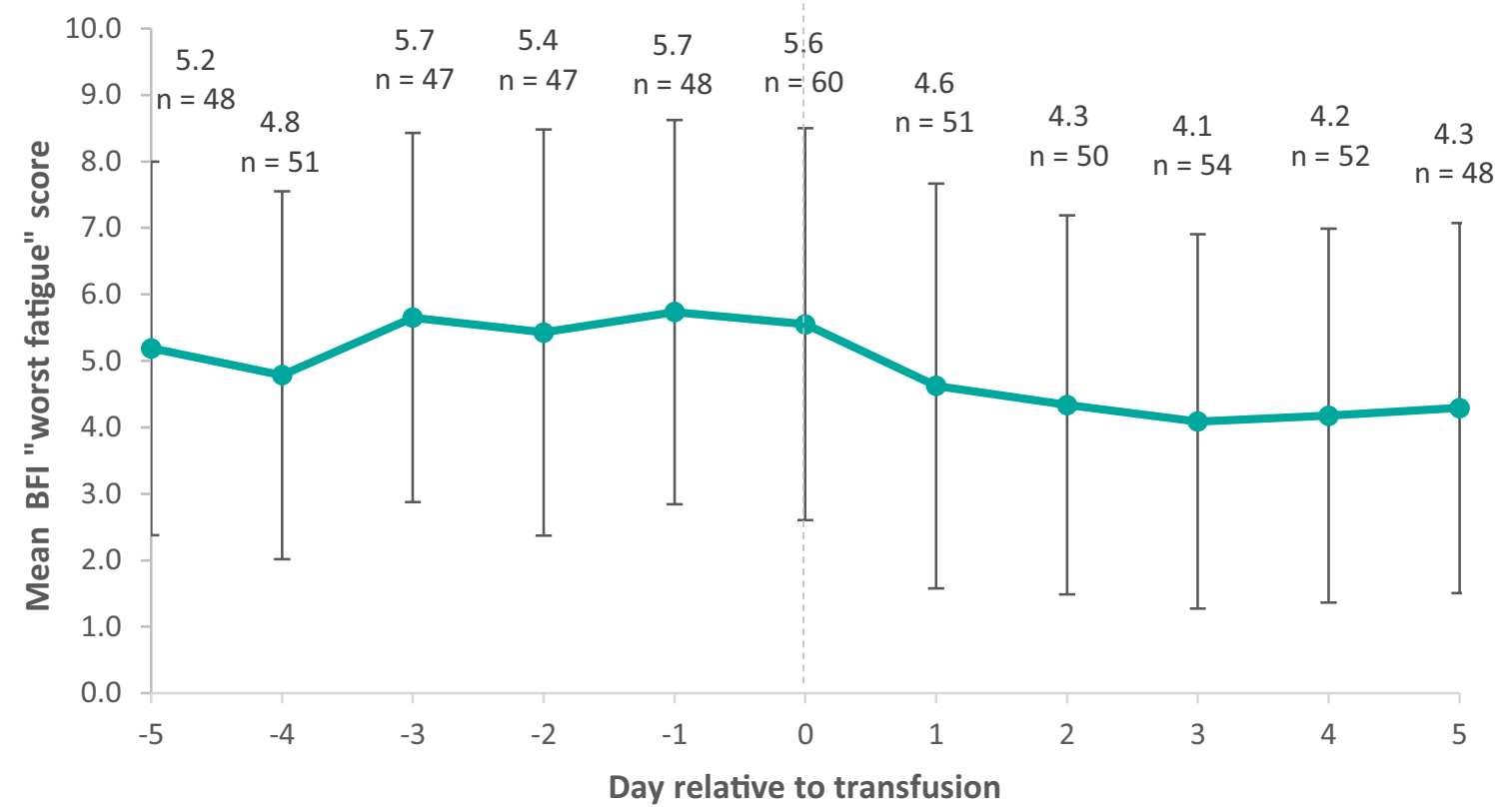

Fig. 4 Brief Fatigue Inventory (BFI) "worst fatigue" score relative to transfusion day. Error bars indicate standard deviation

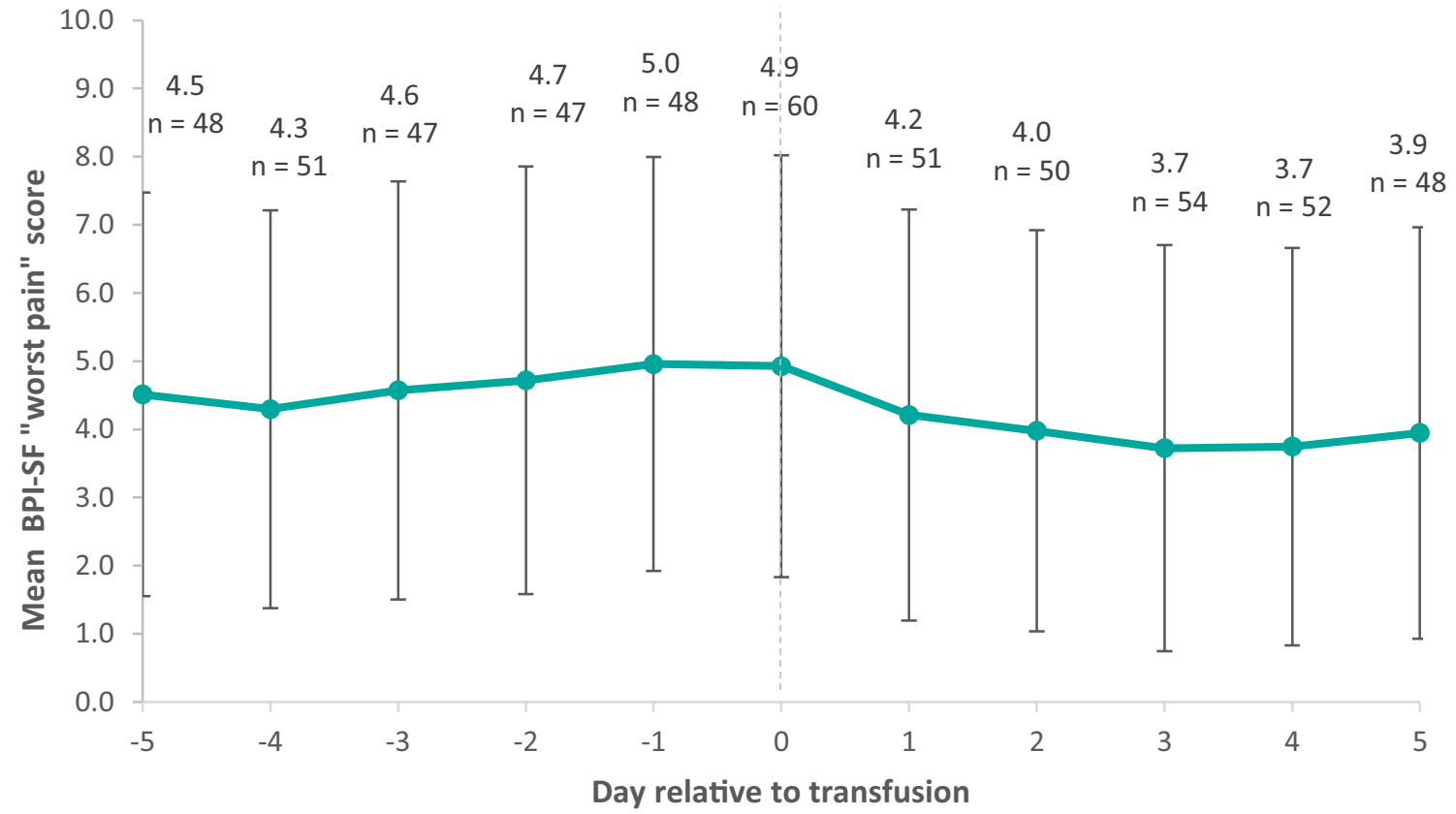

Fig. 5 Brief Pain Inventory Short Form (BPI-SF) “worst pain” score relative to transfusion day. Error bars indicate standard deviation

on transfusion days. Alongside transfusions, organizing payments from health insurance, type- or cross-matching of blood, and arranging childcare were key drivers of time burden. Few other studies have measured the time taken by people with chronic diseases to carry out a comprehensive range of health-related activities [42]. However, the available evidence is consistent with the level of burden we observed, with one review concluding that many people with chronic diseases and their informal caregivers may both be spending at least $2 \mathrm{~h}$ per day on disease management, with some diseases, such as diabetes mellitus, imposing greater time burdens [42].

Overall, fatigue in individuals with TDT, as measured by the BFI, was higher than observed elsewhere in healthy 
controls (5.5, compared with 2.3 for controls) [43], and similar to levels seen in other chronic diseases where time and disease burden are high, including Crohn's disease (4.2) [43], ulcerative colitis (4.1) [43], and rheumatoid arthritis (7.3) [44]. We also saw that the mean worst daily levels of fatigue experienced by individuals with TDT increased in the lead-up to transfusion, before dropping post-transfusion. Although fatigue is a common symptom of TDT, there is an absence of published studies analyzing fatigue in the condition, thus we have been unable to make meaningful comparisons of our results with those of other TDT populations.

Overall HRQoL, as measured by the TranQol, was worse than has been reported previously for TDT populations in North America (51.0, compared with 71.0 for North American patients) [15]; however, it was similar to levels reported in Middle Eastern studies (48.3-58.9) [13, 14, 16]. In our study, respondents' physical functioning domain scores were lowest, mental and family and friend functioning scores were moderate and similar, while academic and professional functioning scores were higher. These differences in domain scores could provide potential target areas for improvements in TDT care.

In our study, the mean worst daily levels of pain experienced by individuals with TDT, as measured by the BPI-SF "worst pain" score, increased in the 5-day period leading up to transfusion, before dropping in the 5-day post-transfusion period. This pattern appears to align with the known waning and rising of hemoglobin levels prior to and following transfusion [1]. Other studies evaluating BPI-SF scores in patients with thalassemia have reported similar levels of pain to those seen in our study. An analysis of North American patients with thalassemia (the majority with $\beta$-thalassemia) enrolled in the Thalassemia Clinical Research Network's Pain Survey reported mean "worst pain" scores of 5.8 over the 9-month study period [45]. In another analysis of the same population, almost half of participants cited blood transfusions as an activity that decreased pain levels [46], which supports the pattern of rising and decreasing pain pre- and post-transfusion that we observed [1].

Several limitations of our study design must be considered when interpreting the results. First, given the app-based approach, the population was restricted to confident smartphone users. This may have excluded some potential participants who were older, lacked access to a smartphone, or had difficulties with vision or dexterity.

The remote app-based approach meant that participant eligibility and accuracy of data could not be directly verified by a clinician. However, the associated risks to data quality were minimized by asking participants specific eligibility questions, setting rules for question responses, and performing checks on the data (e.g., identification and potential removal of outliers) prior to analysis.
Our study was also limited by the fact that each survey was analyzed independently, with participants included in the analysis if they responded to that particular survey, rather than if they responded to all surveys or, at a minimum, the background demographic survey. Caution must therefore be taken when making comparisons between the results of different surveys, as the populations may have been slightly different. However, as at least 73 of the 97 participants registered for the study app responded to each survey, the overlap between survey populations was high, thus this limitation is likely to have had little impact on overall conclusions.

Another factor limiting the quality of our study results was the use of a novel disease-management survey. Although the survey was reviewed by individuals with TDT during development, it was not formally validated. Analysis of survey responses identified several problems. For instance, because participants first had to select certain activities before reporting time data for them, there was no way of being certain whether an absence of data indicated no time spent, non-response to that part of the survey, or the accidental failure to select an activity in the list of available options. Additionally, participants were not asked whether they had dependent children, thus it was difficult to interpret whether the absence of time spent on childcare was because TDT had no impact on time spent, or because the participant had no children. Further refinements and validation would therefore be recommended before the survey was used in future research.

One final area of the study design that may have had undesired effects was the financial reward system used to encourage participant engagement. Financial rewards carry a risk of undermining intrinsic motivation [47], and may encourage false reporting, so must be used carefully. However, the previously mentioned efforts made to verify eligibility and ensure data accuracy reduced the risk of negative consequences.

Although the app-based approach taken in this study introduced several potential limitations, it did provide some advantages over in-person methods, which should be noted. The ease with which participants could learn about the study, enroll, and contribute data promoted a diverse and complete dataset, while digital data management and analysis reduced administrative burden and opportunities for human error.

\section{Conclusions}

The patient- and caregiver-reported burden of TDT is high, strongly influenced by disease-management time, fatigue and pain symptoms, and impairment to quality of life. The level of burden appears to differ across the TDT population, driven by differences in treatments received and countryspecific differences in healthcare systems. It is apparent that 
there remains a high unmet need in TDT caused by the burden on patients and their caregivers.

Acknowledgements We thank all participants in the myThalLog study. We also acknowledge the work of all colleagues who assisted in the design and implementation of this study. Editorial assistance in the preparation of this manuscript was provided by Laura Ellis of Vitaccess Ltd.

\section{Declarations}

Funding bluebird bio funded this study and the preparation of this article.

Conflict of interest Clark Paramore is a paid employee of bluebird bio. Laurice Levine is a patient advocate who has received consulting fees from bluebird bio. Emma Bagshaw, Chengyu Ouyang, and Amber Kudlac are paid employees of Vitaccess Ltd; Mark Larkin is the CEO of Vitaccess Ltd. Vitaccess Ltd was paid by bluebird bio to run this study and develop this article. Vitaccess Ltd has also received payment from bluebird bio for consulting not directly related to this article.

Ethics approval Ethics approval for this study was granted by a central independent institutional review board (Salus Institutional Review Board, Austin, TX, USA). The study was performed in accordance with the Declaration of Helsinki.

Consent to participate All participants provided informed consent to take part in this study via the myThalLog app.

Consent for publication All participants provided consent for the publication of de-identified, aggregated data from the study.

Availability of data and material Study data are available on request by contacting Vitaccess Ltd.

Authors' contributions $\mathrm{AK}, \mathrm{ML}, \mathrm{LL}$, and $\mathrm{CP}$ contributed to the design of the study and data acquisition strategy. $\mathrm{CO}$ and $\mathrm{AK}$ led the data analysis. EB assisted with the data analysis and interpretation and drafted this manuscript. All authors reviewed the manuscript, provided feedback, and approved the version to be published.

Open Access This article is licensed under a Creative Commons Attribution-NonCommercial 4.0 International License, which permits any non-commercial use, sharing, adaptation, distribution and reproduction in any medium or format, as long as you give appropriate credit to the original author(s) and the source, provide a link to the Creative Commons licence, and indicate if changes were made. The images or other third party material in this article are included in the article's Creative Commons licence, unless indicated otherwise in a credit line to the material. If material is not included in the article's Creative Commons licence and your intended use is not permitted by statutory regulation or exceeds the permitted use, you will need to obtain permission directly from the copyright holder. To view a copy of this licence, visit http://creativecommons.org/licenses/by-nc/4.0/.

\section{References}

1. Cappellini M, Cohen A, Porter J, Taher A, Viprakasit V. Guidelines for the management of transfusion dependent thalassemia.
2014. https://www.ncbi.nlm.nih.gov/books/NBK269382/. Accessed 28 July 2020.

2. Angelucci E, Matthes-Martin S, Baronciani D, Bernaudin F, Bonanomi S, Cappellini MD, et al. Hematopoietic stem cell transplantation in thalassemia major and sickle cell disease: indications and management recommendations from an international expert panel. Haematologica. 2014;99(5):811-20.

3. Fung EB, Harmatz PR, Milet M, Balasa V, Ballas SK, Casella JF, et al. Disparity in the management of iron overload between patients with sickle cell disease and thalassemia who received transfusions. Transfusion. 2008;48(9):1971-80.

4. Riewpaiboon A, Nuchprayoon I, Torcharus K, Indaratna K, Thavorncharoensap M, Ubol B-O. Economic burden of betathalassemia/Hb E and beta-thalassemia major in Thai children. BMC Res Notes. 2010;3:29.

5. Hisam A, Khan NUS, Tariq NA, Irfan H, Arif B, Noor M. Perceived stress and monetary burden among thalassemia patients and their caregivers. Pak J Med Sci. 2018;34(4):901-6.

6. Thuret I, Hacini M, Pegourie-Bandelier B, Gardembas-Pain M, Bisot-Locard S, Merlat-Guitard A, et al. Socio-psychological impact of infused iron chelation therapy with deferoxamine in metropolitan France: ISOSFER study results. Hematology (Amsterdam, Netherlands). 2009;14(6):315-22.

7. Clarke SA, Skinner R, Guest J, Darbyshire P, Cooper J, Shah F, et al. Health-related quality of life and financial impact of caring for a child with thalassaemia major in the UK. Child Care Health Dev. 2010;36(1):118-22.

8. Gollo G, Savioli G, Balocco M, Venturino C, Boeri E, Costantini $\mathrm{M}$, et al. Changes in the quality of life of people with thalassemia major between 2001 and 2009. Patient Prefer Adher. 2013;7:231-6.

9. Sobota A, Yamashita R, Xu Y, Trachtenberg F, Kohlbry P, Kleinert DA, et al. Quality of life in thalassemia: a comparison of SF-36 results from the thalassemia longitudinal cohort to reported literature and the US norms. Am J Hematol. 2011;86(1):92-5.

10. Messina G, Colombo E, Cassinerio E, Ferri F, Curti R, Altamura $\mathrm{C}$, et al. Psychosocial aspects and psychiatric disorders in young adult with thalassemia major. Intern Emerg Med. 2008;3(4):339-43.

11. Vlachaki E, Neokleous N, Paspali D, Vetsiou E, Onoufriadis E, Sousos N, et al. Evaluation of mental health and physical pain in patients with beta-thalassemia major in northern Greece. Hemoglobin. 2015;39(3):169-72.

12. Toret E, Karadas NO, Gokce NO, Kaygusuz A, Karapinar TH, Oymak Y, et al. Quality of life and depression in Turkish patients with beta-thalassemia major: a cross-sectional study. Hemoglobin. 2018;42(5-6):326-9.

13. Yasmeen H, Hasnain S. Quality of life of Pakistani children with beta-thalassemia major. Hemoglobin. 2018;42(5-6):320-5.

14. Yousafzai Y, Roghani A, Khan N, Shah I, Khan S, Taj A. Quality of life and its determinants in transfusion dependent thalassemia. Pak J Physiol. 2018;13(3):64-7.

15. Klaassen RJ, Barrowman N, Merelles-Pulcini M, Vichinsky EP, Sweeters N, Kirby-Allen M, et al. Validation and reliability of a disease-specific quality of life measure (the TranQol) in adults and children with thalassaemia major. Br J Haematol. 2014;164(3):431-7.

16. Adib-Hajbagher M, Poormansouri S, Ahmadi M. Psychometric evaluation of the Persian translation of the Thalassemia-Specific Quality of Life Questionnaire. J Nurs Meas. 2017;3:E202-17.

17. Steinhubl SR, McGovern P, Dylan J, Topol EJ. The digitised clinical trial. Lancet. 2017;390(10108):2135.

18. Dorsey ER, Yvonne Chan Y-F, McConnell MV, Shaw SY, Trister $\mathrm{AD}$, Friend SH. The use of smartphones for health research. Acad Med. 2017;92(2):157-60. 
19. Porter J, Bowden DK, Economou M, Troncy J, Ganser A, Habr D, et al. Health-related quality of life, treatment satisfaction, adherence and persistence in beta-thalassemia and myelodysplastic syndrome patients with iron overload receiving deferasirox: results from the EPIC clinical trial. Anemia. 2012;2012:297641.

20. Trachtenberg FL, Martin M, Green S, Oliveros O, Carson S, Gerstenberger $\mathrm{E}$, et al. Use of electronic data collection to assess pain in thalassaemia: a feasibility study. Int J Palliat Nurs. 2012;18(9):441-5

21. Klaassen R. Introducing the Tran Qol: a new disease-specific quality of life measure for children and adults with thalassemia major. J Blood Disord Transfus. 2013. https://doi.org/10.4172/21559864.1000150.

22. Mendoza TR, Wang XS, Cleeland CS, Morrissey M, Johnson BA, Wendt JK, et al. The rapid assessment of fatigue severity in cancer patients. Cancer. 1999;85(5):1186-96.

23. Yun YH, Lee MK, Chun HN, Lee YM, Park SM, Mendoza TR, et al. Fatigue in the general Korean population: application and normative data of the Brief Fatigue Inventory. J Pain Symptom Manag. 2008;36(3):259-67.

24. Mendoza TR, Laudico AV, Wang XS, Guo H, Matsuda ML, Yosuico VD, et al. Assessment of fatigue in cancer patients and community dwellers: validation study of the Filipino version of the brief fatigue inventory. Oncology. 2010;79(1-2):112-7.

25. Catania G, Bell C, Ottonelli S, Marchetti M, Bryce J, Grossi A, et al. Cancer-related fatigue in Italian cancer patients: validation of the Italian version of the Brief Fatigue Inventory (BFI). Support Care Cancer. 2013;21(2):413-9.

26. Murphy SL, Lyden AK, Smith DM, Dong Q, Koliba JF. Effects of a tailored activity pacing intervention on pain and fatigue for adults with osteoarthritis. Am J Occup Ther. 2010;64(6):869-76.

27. Shuman-Paretsky MJ, Belser-Ehrlich J, Holtzer R. Psychometric properties of the Brief Fatigue Inventory in community-dwelling older adults. Arch Phys Med Rehabil. 2014;95(8):1533-9.

28. Anderson KO, Getto CJ, Mendoza TR, Palmer SN, Wang XS, Reyes-Gibby CC, et al. Fatigue and sleep disturbance in patients with cancer, patients with clinical depression, and communitydwelling adults. J Pain Symptom Manag. 2003;25(4):307-18.

29. Reyes-Gibby CC, Mendoza TR, Wang S, Anderson KO, Cleeland CS. Pain and fatigue in community-dwelling adults. Pain Med. 2003;4(3):231-7.

30. Brown E, Hurlow A, Rahman A, Closs SJ, Bennett M. Assessment of fatigue after blood transfusion in palliative care patients: a feasibility study. J Palliat Med. 2010;13:1327-30.

31. Aslani E, Georgios L, Tsironi M. The measurement of fatigue in hemoglobinopathies: a systematic review of fatigue measures. Int J Caring Sci. 2018;11(3):1970-81.

32. Cleeland CS, Ryan KM. Pain assessment: global use of the Brief Pain Inventory. Ann Acad Med Singap. 1994;23(2):129-38.

33. de Andres AJ, Cruces Prado LM, Canos Verdecho MA, Penide Villanueva L, Del Valle HM, Herdman M, et al.
Validation of the short form of the Brief Pain Inventory (BPI$\mathrm{SF})$ in Spanish patients with non-cancer-related pain. Pain Pract. 2015; 15(7):643-53.

34. Tan G, Jensen MP, Thornby JI, Shanti BF. Validation of the Brief Pain Inventory for chronic nonmalignant pain. J Pain. 2004;5(2):133-7.

35. Mendoza T, Mayne T, Rublee D, Cleeland C. Reliability and validity of a modified Brief Pain Inventory short form in patients with osteoarthritis. Eur J Pain. 2006;10(4):353-61.

36. Zelman DC, Gore M, Dukes E, Tai KS, Brandenburg N. Validation of a modified version of the brief pain inventory for painful diabetic peripheral neuropathy. J Pain Symptom Manag. 2005;29(4):401-10.

37. Keller S, Bann CM, Dodd SL, Schein J, Mendoza TR, Cleeland CS. Validity of the brief pain inventory for use in documenting the outcomes of patients with noncancer pain. Clin J Pain. 2004;20(5):309-18.

38. Kazdin AE, Bootzin RR. The token economy: an evaluative review. J Appl Behav Anal. 1972;5(3):343-72.

39. Morford ZH, Witts BN, Killingsworth KJ, Alavosius MP. Gamification: the intersection between behavior analysis and game design technologies. Behav Anal. 2014;37(1):25-40.

40. Nordin $\AA$, Taft C, Lundgren-Nilsson $\AA$, Dencker A. Minimal important differences for fatigue patient reported outcome measures: a systematic review. BMC Med Res Methodol. 2016;16(1):62.

41. Mathias SD, Crosby RD, Qian Y, Jiang Q, Dansey R, Chung K. Estimating minimally important differences for the worst pain rating of the Brief Pain Inventory-Short Form. J Support Oncol. 2011;9(2):72-8.

42. Jowsey T, Yen L, Mathews P. Time spent on health related activities associated with chronic illness: a scoping literature review. BMC Public Health. 2012;12:1044.

43. Yoo S, Jung YS, Park JH, Kim HJ, Cho YK, Sohn CI, et al. Fatigue severity and factors associated with high fatigue levels in Korean patients with inflammatory bowel disease. Gut Liver. 2014;8(2):148-53.

44. Naegeli AN, Sterling KL. PMS58 pilot validation of the Brief Fatigue Inventory "Fatigue at its Worst" item in patients with rheumatoid arthritis. Value Health. 2011;14(7):A313.

45. Oliveros O, Trachtenberg F, Haines D, Gerstenberger E, Martin M, Carson S, et al. Pain over time and its effects on life in thalassemia. Am J Hematol. 2013;88(11):939-43.

46. Haines D, Martin M, Carson S, Oliveros O, Green S, Coates T, et al. Pain in thalassaemia: the effects of age on pain frequency and severity. Br J Haematol. 2013;160(5):680-7.

47. Cameron J, Banko KM, Pierce WD. Pervasive negative effects of rewards on intrinsic motivation: the myth continues. Behav Anal. 2001;24(1):1-44. 